\title{
Post-regulation effect on factors driving environmental disclosures among Chinese listed \\ firms
}

\begin{abstract}
Purpose: This study re-examines the factors that affect the level of Environmental Information Disclosures (EID) following the issuance of the "Environmental Information Disclosure Guidelines for Chinese Listed Companies".

Design/methodology/approach: The study is underpinned by stakeholder and legitimacy theories. Level of EID was measured for 100 Chinese companies using a scoring system and content analysis of their annual reports. The study explored the effect of ownership structure, managerial shareholding, economic power and industry classification on the level of EID using panel regression.

Findings: The study revealed that with clearly spelt out guidelines, Chinese companies are prepared to disclose environmental information regardless of their economic power. We find that the overall level of EID in China remains lower when compared with developed economies. The findings are robust across several econometric models that sufficiently address various endogeneity problems.

Originality/value: This paper contributes to the existing literature by using new and updated data to re-examine the factors that affect the level of EID among Chinese listed companies. The study is important and timely as it covers the period of 2014 - 2016 which is after the Chinese government strengthened the enforcement of EID. It highlights the effects of new regulations and underscored areas that still require government attention to foster effective environmental protection.
\end{abstract}

keywords: China, Environmental disclosure, Legitimacy theory, Stakeholder theory, Post-regulation 


\section{Introduction}

This study explores the ways in which new environmental regulations affect Environmental Information Disclosure (EID) by listed companies in China. EID has become an efficient way to communicate with stakeholders and an essential research area in the last decades with most of such studies focusing on developed countries (Adelopo and Yekini, 2018).

Over the last twenty years, China has begun to experience high GDP growth. In 2011, the total GDP in China reached 5.93 trillion US dollars, with China overtaking Japan and becoming the second largest economy in the world (Wang et al., 2015). The rapid growth of Chinese economy with the resultant environmental deterioration, led the Chinese government to implement policies that could encourage companies to disclose environmental information (Meng et al., 2013). The disclosure was initially made compulsory only for companies causing pollution under the regulation of the National Environmental Protection Agency (NEPA), while other companies were encouraged to disclose voluntarily (Hu and Karbhari, 2015). The implication was that only few of such companies voluntarily disclosed environmental information in their annual reports as against what is found in developed countries (Hu and Karbhari, 2015). For example, Baboukardos (2018) observed the moderating effect of well spelt-out regulation on EID for French companies and encouraged the adoption of same for other countries. The new government regulations in China among other things therefore, placed a lot of pressure on Chinese listed companies to disclose environmental information (Meng et al., 2013)

The aim of this study is to examine the extent to which the new regulations have motivated EID among listed companies in China and to generate deeper insights on the status of the level of EID generally both after the regulations and in recent years. To date there has been limited work on this subject on Chinese market. According to Hu and Karbhari (2015), most extant studies on the subject, lack sufficient information and are qualitative in nature. In addition, the data used in the few quantitative studies (Liu et al., 2010; Meng et al., 2013; Zeng et al., 2010) found in literature is dated and mainly around 2000 to 2008, which was the period when the enforcement of EID disclosure was weak in China. In other words, the data does not cover the period when the China State Environmental Protection Administration (SEPA) issued "Environmental Information Disclosure Guidelines for Chinese Listed Companies" (otherwise known as EID Guidelines), which further strengthened the regulation on EID in 2010 (Meng et al., 2013). This study is therefore important as it uses the most 
recent data to re-examine the current situation regarding the level of EID by Chinese listed companies.

This research contributes to the existing literature on EID by using new dataset covering the period 2014-2016. Our paper departs from the existing literature on EID as most of them are carried out on developed markets where principles rather than rule is the norm. This allows us to show the effects of regulations on disclosures and in particular the advantage of a well spelt out guideline. The study proceeds in section 2 with a literature review, followed by the study design in section 3 , result and analysis in section 4 and conclusion in section 5.

\section{Literature review}

\subsection{Theoretical context}

Legitimacy and stakeholder theories are the two dominant theories for the research of EID. While some studies (Campbell, 2000; Cho and Patten, 2007; Yekini et al., 2015) have applied them independently, others (Dean and Brown, 1995; Christmann and Taylor, 2001) have jointly considered the two theories in their explanation of firms' practice of social and environmental disclosure. Legitimacy theory originated from the interaction between the firms and the society by the social contract assumptions (Hu and Karbhari, 2015). The social contract assumption supposed that firms and society are bound by an implied contract that legitimize the operations of the firm within a society and that failure to meet the expectations of the society may cause the firm to be penalized by the society (Deegan, 2002).

Stakeholder theory (Freeman, 1984), on the other hand, states that the interest of those who will affect or will be affected by the firm's operation should be taken into consideration in decision making. These stakeholders, including creditors, consumers, shareholders, employees, suppliers and the society at large, can therefore be viewed as people who are interested in company's environmental and societal operations. However, while legitimacy theory is viewed as a kind of social dynamics, stakeholder theory emphasizes the potent stakeholders in the social dynamics (Belal, 2002), and these two theories tend to be better considered as two overlapping standpoints that supply distinct and valuable viewpoints for EID research (Yekini, 2012).

Woodward et al. (1996) argue that both stakeholder and legitimacy theories view an organisation as part of the society, however the two theories focused on different perspectives. Yekini (2012:62) 
assert that while "legitimacy theory looks at the corporation's contractual obligation to society as a whole, stakeholder theory makes a distinction between groups within society and recognise that some groups are more powerful than others" and could therefore impact greatly on the extent of the firm's exercise of its contractual obligation as suggested by legitimacy theory. Consequently, the two theories can be said to be both complimentary and interlocking. They are interlocking in the sense that; they both impact on one another. For example, the pressure from stakeholders such as government, consumers, shareholders, employees and so on, necessitated the firms desire to fulfil its contractual obligation to the society in the form of environmental activities to legitimize its operations. In addition, Yekini (2012) argues that since the power to confer legitimacy lies with the society as the stakeholder group, the legitimizing activity e.g. environmental activity, must receive their full acceptance and approval before it can achieve its legitimizing effect. It is this interlocking of the two theories that inform EID (see Figure 1 for illustration).

\section{$[<<<<$ Figure 1 about here $>>>>]$}

Previous studies (such as Dean and Brown, 1995; Christmann and Taylor, 2001) considered the conjoined theory (stakeholder and legitimacy) to explain firms' practices of social and environmental disclosure and divided the factors that can influence the level of EID into internal and external factors. The external factors, underpinned by stakeholder theory are; government, shareholder, creditor, consumer and supplier, competitor, auditor, manager amongst others (Mitchell et al., 1997; Belal, 2002). The internal factors are underpinned by legitimacy theory and includes such factors as, firm size, age, profitability, financial leverage, industry, market amongst others (Cho and Patten, 2007; Liu and Anbumozhi, 2009). The two theories combined, therefore, provide powerful theoretical framework for EID. The conjoined theory revealed that firms tend to disclose EID for legitimizing relationships between organization and society (Cho and Patten, 2007) to meet society's/stakeholders' expectations (Yekini et al., 2017).

\subsection{Prior studies on China}

There is a plethora of studies on the determinants of the level of EID of listed companies for developed countries such as Australia and New Zealand (Hackston and Milne, 1996; Deegan and 
Gordon, 1996; Brown and Deegan, 1998); USA (Clarkson et al., 2008; Cho and Patten, 2007; Freedman and Stagliano, 2008); UK (Gray et al., 1995; Hasseldine et al., 2005; Toms, 2002); Continental Europe (Branco and Rodrigues, 2008; Cormier and Magnan, 2003; Gamerschlag et al., 2010), Asia and other developing countries (Hossain et al., 1994; Huang and Kung, 2010). However, only few studies (Zeng et al., 2010; Zhang et al., 2011; Chen and Kong, 2011; Meng et al., 2013) exist for China. Most studies on China were conducted at the period when EID was very weak in China.

The first regulation on EID was issued in 2007 by SEPA, requesting companies to disclose in their annual reports, information on pollution and action taken by them to protect the environment. Prior to this, disclosure was based on companies' social responsibility consciousness. In addition to the SEPA rules, Shanghai Stock Exchange, in 2008, issued further guide requiring all companies listed on it, to mandatorily disclose information related to environmental protection. SEPA further issued EID Guidelines in 2010 to provide further details on mandatory and voluntary disclosure for listed companies. This resulted in more companies disclosing EID since 2010 (Zeng et al., 2010; Hu and Karbhari 2015). Especially since violations may result in penalty (Meng et al., 2013). These changes have reflected significantly on the level of EID across China.

Although, several studies have examined post-regulation effect in other countries (Baboukardos, 2018; Gintschel and Markov, 2004; Clarkson et al., 2008; Dean and Brown, 1995), we expect that post-regulation effect in China will be different because China's economic setting is quite distinct from other countries. China's regional economies are undeveloped hence regional practices regarding EID differs considerably (Zhang et al., 2010). The regulation is expected to even out the imbalanced development across the country, thus narrowing regional differences (Zhang and Guan, 2009). Furthermore, the focus of this paper is to explore the effect of the new regulations on established factors driving EID. Many studies have explored different factors affecting the level of EID, such as economic performance (Cormier and Magnan, 2003; Nollet et al., 2016), environmental performance (Gamerschlag et al., 2010; Branco and Rodrigues, 2008), and ownership types (Meng et al., 2013) amongst others. Our aim is to examine whether the new regulations and guidelines influence the extent to which these factors drive EID.

Ownership structure and EID. Several studies have shown that ownership structure is one of the decisive factors influencing the level of EID (Meng et al., 2013; Adelopo and Yekini, 2018). 
However, Firms in China are separated into state-owned enterprises (SOE) and private enterprises (non-SOE). There have been more studies (for example, Zeng et al., 2012; Meng et al., 2013; Chang et al., 2015) on the performance of EID for SOEs than for non-SOEs. These studies indicate that compared with non-SOEs, SOEs have funding and policy support from the government and attract more public concerns, hence they are under more pressure to disclose more to their key stakeholders consistent with stakeholder theory. However, while Zeng et al. (2012) and Meng et al. (2013) found positive and significant relationship between government pressure and level of EID for SOEs, Hu et al. (2018) and Chen and Kong (2011) found no relationship. Hu et al. (2018) noted that the this could be due to the political legitimacy that SOEs enjoy while Chen and Kong (2011) argue that non-SOEs ought to disclose more EID than SOEs since SOEs already have social welfare and government support, hence, should be less concerned with reputation management, while non-SOEs should disclose more to attract investment. This argument contradicts the stakeholder theory's view of a firm. Stakeholder theory predicts that firms will strive to meet the expectation of their powerful or highly salient stakeholders (Mitchell et al., 1997; Yekini et al., 2015) which in the case of SOEs are the government and the public. Similarly, Meng et al. (2013), in supporting their proposed pressure-legitimacy theory, show that government ownership has a positive association with EID of SOEs irrespective of the "size of government holdings" (Meng et al., 2013:220). Moreover, the new guideline for SOEs require SOEs to be more responsive to social and environmental responsibility ( $\mathrm{Li}$ et al., 2013). We therefore expect that, given the new regulations and guidelines, SOEs will likely disclose more environmental information than non-SOEs.

Managerial shareholdings and EID. One of the postulations of stakeholder theorist is a holistic approach to managing firms to achieve good corporate governance. One of the key corporate governance mechanisms to achieve this is the alignment of managers' interest to that of the shareholders in order to ensure that managers protect the interest of the shareholders at all times (Healy and Palepu, 2001; Chen and Kong, 2011). One such mechanism is equity incentives given as one of the remuneration packages of managers. This has the advantage of evoking the manager's interest to the utmost. Thus, managers will devote themselves to their company and focus on the financial and social aims to ensure sustainable growth and development of the firm (Yu, 2007). However, this may influence corporate disclosure strategies. For example, Chen and Kong (2011) found a positive 
relationship between managerial shareholding and the level of EID. They argue that managers who possess shareholdings of a corporation will undertake sustainable development and environmental disclosure since they have also become part owners of the firm. Healy and Palepu (2001), on the other hand, provided conflicting evidence from extant literature, of manager's behavior to voluntary disclosures where stock option compensation is involved. With Chinese context, we anticipate positive relationship between managerial shareholding and the level of EID.

Economic Power and EID. Economic performance has been widely considered as a factor associated with the level of EID (Clarkson et al., 2008; Qiu et al., 2016; Nollet et al., 2016). Legitimacy theorist posit that high performing firms are under more pressure to legitimize their operations to avoid disruptions (Campbell, 2000; Yekini, 2012). The literature presents diverse measurement for economic performance. While some use income growth rate, others use profit margin, return on equity and return on assets amongst others. However, some scholars argue that the economic power of a firm depend not only on its profitability but also on its solvency (Roberts, 1992). Hence financial leverage has been used in earlier studies as a measure of solvency and financial capability. The advocates of financial leverage (see Roberts, 1992 and Hossain et al., 1994 for example) argued that creditors who provide loans to firms are powerful stakeholders and could demand disclosures of certain information including EID. Roberts (1992) finds a positive relationship between company's debt financing and the level of EID. Hossain et al. (1994) report that financial leverage plays an important role in the level of EID as it reflects the solvency of the company. However, Cormier and Magnan (2003) found a negative relationship, while Alsaeed (2006) found no significant relationship between financial leverage and the level of EID. However, since the performance of a firm is closely linked with its solvency i.e. its financial capability (Al-Tuwaijri, et al., 2004), we combine financial leverage and profit margin as our measure of economic power. This is because the costly environmental programs undertaken by firms will depend largely on their solvency and financial conditions (Qiu et al., 2016). Consequently, any measure used to protect the environment or for energy saving are inseparable from financial capability of the firm.

Industry classification and EID. Apart from economic power, industry classification has also played a crucial role in terms of the studies of EID. Different industries have different environmental performance due to their different characteristics (Deegan, 2002; Roberts, 1992). Firms with serious 
environmental pollution have more motivations to disclose environmental information for the sake of avoiding any related costs enforced by society and government (Deegan, 2002; Deegan and Gordon, 1996). Yekini and Jallow (2012) observed that high-profile industries tend to make higher level of EID to meet public expectations. However, Alsaeed (2006), found no significant relationship between industry types and the level of EID. Branco and Rodrigues (2008) in their study of CSR of Portuguese firms found significant relationships. Similarly, Gamerschlag et al. (2010) find that firms in the energy supply and consumer industry seem to disclose more environmental information than those in service and other industries which is consistent with the findings of a recent study by Yekini et al. (2015). In the current study, we explore the issue further in a new regulatory environment. We expect the high polluters to disclose more given the specific focus of the new regulations on pollution.

\section{Study design}

\subsection{Sample and data}

The study focused on manufacturing firms chosen from Chinese "A" share in Shanghai and Shenzhen stock exchanges for 2014 to 2016. Manufacturing firms are chosen because they produce more polluted externalities than other industries. Sample period of 2014 to 2016 was selected to obtain insights into the developments and changes in the performance of EID of listed companies after SEPA issued EID Guidelines to strengthen the regulation of EID of corporations and to see how the issuance of new guidelines on EID for listed companies by the Ministry of Environmental Protection (MEP) in 2010 has affected the level of EID.

To collect data, the list of all listed company from the China Stock Market and Accounting Research (CSMAR) database was downloaded. This database is a multi-level capital market information database and has all information on the Chinese Securities Regulatory Commission. To ensure representativeness, samples were selected from both polluting and non-polluting industries. Industries classified as polluting by MEP are petroleum and plastic, chemical, paper making and printing, mining, medicine and biological products, drink and food, textile and clothing (Zeng et al., 2012). Companies with significant trading losses for the past 2 years and/or with negative equity were not included in the sample. This is to avoid abnormality and extreme outliers in the sample. Similarly, companies for which all the required data for the analysis could not be obtained were also left out. 
Overall, the sample consist of 100 companies all drawn from the manufacturing industry. Financial data for these companies were obtained from the CSMAR database, while data for EID were obtained using content analysis from companies' annual reports, sustainability and social responsibility reports. Table 1 below shows the companies based on exchange they were listed on.

$$
[<<<<\text { Table } 1 \text { about here }>>>>]
$$

Table 1 also shows a mean EID score of 9.43 for Shenzhen stock exchange and 10.53 for Shanghai stock exchange. Indicating that more company on Shanghai stock exchange disclose more EID than Shenzhen. A plausible explanation could be because Shanghai stock exchange published guidelines for all the companies listed on it on how to implement the guidelines issued by State council on strengthening environmental protection. The guideline was also meant to encourage all listed companies in China to actively fulfill their social responsibility in protecting the environment.

\subsection{Model specification}

We specified a fixed effect (FE) panel regression model for our analysis given that our data is both cross-sectional and time-series in nature. FE has the benefit of controlling for any time invariant unobservable variable. It assumes that such variables are unique to each firm and therefore consolidated in the model's intercept (Greene, 2008). Our model with all the variables is specified as follows:

$$
\begin{aligned}
\text { EID level }_{i t}= & \alpha_{0}+\beta_{1} \mathrm{SOEs}_{i t}+\beta_{2} \mathrm{MAN}_{i t}+\beta_{3} \mathrm{LEV}_{i t}+\beta_{4} \mathrm{PM}_{i t}+\beta_{5} \mathrm{IND}_{i t}+\gamma_{1} \mathrm{SIZE}_{i t} \\
& +\gamma_{2} \mathrm{AGE}_{i t}+\gamma_{3} \mathrm{ROA}_{i t}+\gamma_{4} \mathrm{SE}_{i t}+\epsilon_{i t}
\end{aligned}
$$

Table 2 presents the definitions and measurement of the independent, dependent and control variables in our model.

$[<<<<$ Table 2 about here $>>>>]$

\subsection{The hypotheses}

Following from the literature review in section 2 and the discussions on the determinants of the level 
of EID in China, we formulated the following hypotheses to be tested using the FE model:

H1: SOEs are likely to disclose more environmental information than non-SOEs.

H2: Firms with higher managerial ownership are more likely to disclose more EID than firms with lower managerial ownership.

H3: Firms with better economic power are likely to disclose more EID than their counterparts.

H4: High polluting firms are likely to disclose more level of environmental information than their low polluting counterparts.

\subsection{Dependent variable measurement}

The dependent variable is the level of EID disclosed. We measure the level of disclosure following the guidelines produced by SEPA in 2007 and MEP in 2010. The guideline specifies key areas in which EID is necessary. Based on these new guidelines, we identified eight items to measure the level of EID. They are presented in Table 3 .

$$
[<<<<\text { Table } 3 \text { about here }>>>>]
$$

Content analysis was employed in this study for the collection of EID data. Content analysis have been used extensively in previous similar studies on EID (Beattie et al., 2004; Aerts and Cormier, 2009; Hooks \& van Staden 2011; Yekini et al., 2015). It is defined as a "data collection method of codifying the content of a narrative report using selected criteria or decision rules, thereby deriving a quantitative scale, which then permits further analysis" (Yekini et al., 2015:255). We adopted content analysis in the study because we regard it as an objective and systematic technique that would allow for an objective quantitative analysis. This is because it can be used to convert textual data into quantitative data through an objective and methodical way (Krippendorff, 2004). We obtain information on each item by applying a scoring system similar to that adopted by Yekini et al. (2015). The score ranges from 0 to 3; 0 being no information is provided on EID in company's annual report and 1 means information provided is non-monetary and general in nature such as general description of EID activities; 2 represents specific non-monetary information such as detailed plans and goals; while 3 is monetary information in addition to specific and detailed plan. The total score of a company could therefore range between 0 and 24. The higher the score the greater the extent of information disclosure. Table 4 shows the mean distribution of the level of disclosure for each item. To ensure objectivity and 
consistency, we maintained clear scoring instructions and ensured that scoring was done over several months by researchers experienced in content analysis-based studies. We also ensured that the alpha coefficient (inter-coder agreement) is greater than $85 \%$ (Krippendorff, 2004).

$$
[<<<<\text { Table } 4 \text { about here }>>>>]
$$

Table 4 revealed that there are more disclosures on expenditure associated with environmental protection (ENPR) with the highest mean of 1.89 while government financial support (GFS) has the lowest mean of 0.31 . The lower GFS could be an indication that most of the companies have no governmental funding on environmental protection.

\section{Results and Analysis}

\subsection{Descriptive statistics}

Table 5 shows that the level of EID ranges from 0 to 24 with an average of 10.11 during the sample period of $2014-2016$. The findings indicate that the level of EID has largely improved compared to the prior studies in China, where the mean value of EID was 1.13 and 3.02 between 2006 to 2008 in Meng et al. (2013) and Zeng et al. (2012) respectively. On average managers own 3.9\% shares within the firms with a range from $0 \%$ to $95 \%$. Leverage ratio (LEV) for many companies in the sample is in the region of 51\%. While, this is an improvement to the 56\% in Meng et al. (2013), some having as high as $90 \%$ suggest that most of the sampled firms have relatively high financial gearing consistent with Zeng et al. (2012). The profit margin (PM), has an extensive range from $-76.8 \%$ to $38.95 \%$ with majority of the companies with approximately $6 \%$ which is an improvement to the $3 \%$ in Meng et al. (2013). The Pearson Correlation presented in Table 6, indicates low correlation between all the explanatory variables suggesting that multicollinearity is not a concern. Notwithstanding we computed the variance inflation factor (VIF) for all variables. Our results are below the threshold of 10 for all variables, hence confirming that multicollinearity, if at all existing, is of little concern.

$$
\begin{aligned}
& {[<<<<\text { Table } 5 \text { about here }>>>>]} \\
& {[<<<<\text { Table } 6 \text { about here }>>>>]}
\end{aligned}
$$




\subsection{Regression results}

SOEs and EID: With regards to Hypothesis 1, the results in Table 7 reveal that SOE have a coefficient of 2.594 indicating a strong positive relationship with EID and significant at 1\% level. The results confirm the $\mathrm{H} 1$ that SOEs will disclose more environmental information than non-SOEs. The result contradicts the argument by Chen and Kong (2011) but confirms that of Zeng et al. (2012) and Meng et al. (2013). Chen and Kong (2011) argue that since the private companies are more likely to engage in reputation building in order to attract investment and patronage from the public, they are likely to disclose more EID than SOEs. Arguing further that since SOEs are well supported they should have less concern with reputation management. In contrast, Zeng et al. (2012) and Meng et al. (2013) both argue that SOEs are expected to disclose more since they have more social responsibilities than private companies and have more funding and policy support from the government. Our findings support this argument which is also in line with legitimacy and stakeholder theories.

MAN, and EID: Hypothesis 2 examined the relationship between managerial ownership and the level of EID. The findings in Table 7 show that MAN is significantly and positively associated with EID which is consistent with the study by Chen and Kong (2011). More specifically, In Model 1 of Table 7, MAN has a positive coefficient of 4.964 and significant at 5\% but became marginally significant with the exclusion of SOE from the equation in Model 2. The plausible reason for MAN becoming less significant might be because majority of the SOEs have no manager options since their shareholdings comprise mainly of government holdings, while the opposite is the case with private firms. Given the fact that the majority of private firms have low level of EID, it's likely that the more the private firms in the sample, the more the existence of manager options and the less the importance attached to EID.

Economic Power and EID: Hypothesis 3 examined the relationship between economic power and EID with leverage and profit margin as indicators of economic power. The results in Table 7, show both variables as having inverse relationship with EID. The relationship is also only marginally significant in both cases. The inverse LEV/EID relationship is not consistent with earlier studies (Roberts, 1992 and Hossain et al., 1994) who both found positive and significant relationships but consistent with the findings from more recent studies; Cormier and Magnan (2003) and Alsaeed (2006) 
who both found negative and insignificant relationships. Similarly, the findings for the PM/EID relationship, while not consistent with that of Roberts (1992), is consistent with a recent study by Chen and Kong (2011) who also found insignificant relationship with a negative coefficient. At a glance, we may attribute these inconsistencies to the fact that Roberts (1992) and Hossain et al. (1994) studies are dated and conducted on data from developed countries, some recent studies Yekini and Jallow (2012), Yekini et al. (2017) also found inverse but significant relationship between economic variables with the level of EID in the UK - a developed economy context. However, the plausible reason for an inverse relationship in the current study could be that most Chinese companies sampled are, generally, not influenced by their economic power in their decision to engage in or disclose environmental information which contradicts most extant literature on EID.

Industrial classification and EID: Hypothesis 4 examined industry effect on the level of EID. Consistent with previous studies (Gamerschlag et al., 2010; Yekini and Jallow, 2012; Yekini et al., 2015) the hypothesis is supported by the results. The results show a significant positive relationship at $1 \%$ level to EID. Suggesting that similar to developed economies, industry classification of listed Chinese companies also have significant effect on the level of EID, polluting industries tend to disclose more information on EID than non-polluting industries.

$$
[<<<<\text { Table } 7 \text { about here }>>>>]
$$

\subsection{Additional analysis and robustness check}

Following our initial findings on the economic power variables, we subject our main findings in Table 7 to several robustness checks and additional analysis to enhance the reliability and rigour of our investigation; we present these in Table 8 Panels A and B below. In Table 8, we split our data into two on the basis of the stock exchange in which they are listed to see if this has any effect on the level of EID. Panel A presents the results for companies listed on the Shanghai stock exchange while Panel B presents results for companies listed on the Shenzhen stock exchange. The results in Panel A show that SOE has positive and significant effect on the level of EID while MAN and LEV have insignificant effect on the level of EID. IND has positive and significant effect on the level of EID which is consistent with the results reported in Table 7. The results in Panel B is fairly similar to that of Table 7 and all significant variables remained significant while insignificant variables remained insignificant. 
For instance, PM has negative and significant effect on the level of EID, which implies that companies listed in the Shenzhen stock exchange do not increase their EID level even when there is improved economic power. This confirms the fact that the guideline produced by the Shanghai stock exchange had a great impact on the EID level of the companies listed on it to the extent that they engage in and disclose environmental information regardless of their economic power, while the reverse is the case with the Shenzhen companies.

\section{$[<<<<$ Table 8 about here $>>>>]$}

We conduct several additional analyses to check the sensitivity of our results. First, in order to address the potential endogeneity issues that might arise from simultaneous relationship between ownership variables (SOE and MAN), economic power variables (LEV and PM), industry variable (IND) and the level of EID, we estimate lagged-effects model, where this year's EID is influenced by previous year's ownership, economic power, industry variables and control variables. The results shown in Model 10, 11 and 12 of Table 9 are similar to those reported in Model 1, 2 and 3of Table 7, therefore indicating that our findings are fairly robust to estimating a lagged structure.

In addition, we estimate a random-effect model to address the potential heterogeneity across firms. It is suggested that some unobserved firm-level specific factors can affect the level of EID that normal OLS estimation may not be able to fully address (Thomsen et al., 2006). To mitigate the effect of this concerns, Models of 1, 2 and 3 were re-estimated using random-effect and the results shown in Models 13,14 and 15 of Table 9 are fairly consistent.

Finally, to further address the concern of potential endogeneity, Blundell and Bond (1998) suggest that GMM estimator can be used to mitigate this problem. The findings reported in Models 16, 17 and 18 of Table 9 are consistent with those reported in Models 1, 2 and 3 of Table 7, suggesting that our findings are fairly robust to the presence of any possible endogeneity issues. To assess the validation of our findings, we conducted both second-order autocorrelation test AR (2) and Hansen test. Firstly, the AR (2) tests the null hypothesis of no second-order autocorrelation in residuals (Roodman, 2009). We find that AR (2) for all the models reported in Table 9 are insignificant, implying that the residuals in the equations are not serially correlated. Secondly, we use the Hansen test to test whether the model is over-identified (Roodman, 2009). The results of the Hansen test indicate that all the instruments are 
valid.

$$
[<<<<\text { Table } 9 \text { about here }>>>>]
$$

\section{Conclusion}

This study explores the effect of the regulations issued by SEPA and the guideline issued by Shanghai Stock Exchange (SSE) to simplify the requirements of SEPA's regulations on the level of Environmental Information Disclosures (EID) in the annual reports of Chinese listed companies. Using content analysis, the data was obtained from the annual reports of 100 Chinese companies over the period of 2014 to 2016 drawn from both the Shanghai and Shenzhen Stock Exchanges, while the level of EID was measured using a scoring system.

The findings show that the overall level of EID in China is still very low in non-SOEs compared to SOEs. Most disclosures contained simple description without implementation plans/schemes and projects. Disclosure of funds from government are very limited among sampled non-SOE firms, in addition, the average score of disclosure for technical support and waste disposal are low. The lower level of EID in China reflects lack of government and technical support especially for private enterprises. The findings revealed that ownership structure, industry and economic power are significantly related to EID. The SOEs disclose more EID, since government owned the major shares in the SOEs, and they represent the most powerful stakeholders compared with other creditors, so they have great influence on EID. Similarly, since polluted industries have more regulations from the government, they tend to disclose more information in line with legitimacy theory and to avoid punishments. Furthermore, the guidelines published by the Shanghai stock exchange also encouraged more disclosure.

The findings from this study have a number of important implications for government, management of companies and other policy makers. Firstly, government should establish special environmental protection funds for non-SOEs, to help them conduct more environmental protection activities. For example, provide energy saving technology and apply it into company's products to reduce energy usage; give sufficient funds for companies to establish professional environmental facilities to dispose sewage and other wastes. Secondly, government and policy makers should provide clear guidelines for EID by clearly defining what the content of EID should be and should carry out 
periodic audit on the report published by firms. Finally, government should not only monitor the performance of EID of polluted industries but also pay more attention on non-polluting industries.

Management of listed companies also have an important role to play, they should think highly of their corporate strategies on environmental issues. For example, improve the environmental protection consciousness of their employees through regular training making them aware of the relationship between corporate sustainable development and environmental protection. Management needs to set a clear energy-saving and emission reduction targets for the company and ensure that this is reflected in the EID in their annual reports.

Although the results of this study are robust, a number of limitations are identified as follows. Firstly, the scoring system may be subjective, future study may consider alternative ways to measure of EID. Secondly, we used leverage and profit margin as measures of economic power, future studies may consider other variables such as growth rate of revenue and return on equity. Thirdly, this study employed the quantitative approach and the data is mainly collected from company annual reports, future studies could consider using the qualitative approach, such as interviews, case studies, etc.

\section{References}

Adelopo, I. and Yekini, K. (2018) "Guest Editorial on Dimensions in Corporate Disclosure Studies". Accounting Research Journal, 31(1), 2-7.

Aerts, W., and Cormier, D. (2009), 'Media Legitimacy and Corporate Environmental Communication', Accounting, Organizations and Society. 34(1), 1-27.

Alsaeed, K. (2006), 'The Association Between Firm-specific Characteristics and Disclosure: The case of Saudi Arabia', Managerial Auditing Journal. 21(5), 476-496.

Al-Tuwaijri, S. A., Christensen, T. E. and Hughes, K.E. (2004), 'The Relations among

Environmental Disclosure, Environmental Performance, and Economic Performance: A simultaneous equations approach', Accounting, Organizations and Society. 29(5-6), 447-471.

Baboukardos, D. (2018), 'The valuation relevance of environmental performance revisited: The moderating role of environmental provisions'. The British Accounting Review, 50 (2018) 32-47

Beattie, V., McInnes, B., and Fearnley, S. (2004). A methodology for analysing and evaluating narratives in annual reports: a comprehensive descriptive profile and metrics for disclosure quality attributes, Accounting Forum, 28(3), 205-239

Belal, A. (2002), 'Stakeholder Accountability or Stakeholder Management: A review of UK firms' social and ethical accounting, auditing and reporting (SEAAR) practices', Corporate Social Responsibility and Environmental Management. 9(1), 8-25.

Blundell, R. and Bond, S., (1998). Initial conditions and moment restrictions in dynamic panel data 
models, Journal of econometrics, 87: 115-143.

Branco, M., and Rodrigues, L. (2008), 'Factors Influencing Social Responsibility Disclosure by Portuguese Companies', Journal of Business Ethics. 83(4), 685-701.

Brown, N. and Deegan, C. (1998), "The public disclosure of environmental performance information a dual test of media agenda setting theory and legitimacy theory", Accounting and Business Research, 29(1), 21-41

Campbell, D. J., (2000), Legitimacy theory or managerial reality construction? Corporate social disclosure in Marks and Spencer Plc corporate reports, 1969-1997. Accounting Forum, 24(1), 80100

Chang, L., Li, W. Lu, X (2015), 'Government Engagement, Environmental Policy, and Environmental Performance: Evidence from the most polluting Chinese listed firms', Business Strategy and the Environment. 24(1), 1-19.

Chen, H. and Kong, Y. (2011), 'Research on Stakeholders' Pressure on Chinese Listed Company's Environmental Information Disclosure', International Conference on Information Management, Innovation Management and Industrial Engineering. 2011 (1), 347-351.

Cho, C., and Patten, D. (2007), 'The Role Environmental Disclosures as Tools of Legitimacy: A research note', Accounting, Organizations and Society. 32(7/8), 639-647.

Christmann, P., and Taylor, G. (2001), 'Globalization and the Environment: Determinants of firm selfregulation in China', Journal of International Business Studies. 32 (3), 439-458.

Clarkson, P. M., Yue Li, Richardson, G. D. and Vasvari, F. P. (2008), 'Revisiting the Relation between Environmental Performance and Environmental Disclosure: An empirical analysis', Accounting, Organizations and Society. 33(4-5), 303-327.

Cormier, D., and Magnan, M. (2003), 'Environmental Reporting Management: A continental European perspective', Journal of Accounting and Public Policy. 22(1), 43-62.

Dean, T., and Brown, R. (1995), 'Pollution Regulation as a Barrier to New Firm Entry: Initial evidence and implication for future research', The Academy of Management Journal. 38 (1), 288-303.

Deegan, C. (2002), 'Introduction: The legitimating effect of social and environmental disclosures: A theoretical foundation', Accounting, Auditing and Accountability Journal. 15(3), 282-311.

Deegan, C., and Gordon, B. (1996), 'A Study of the Environmental Disclosures Practices of Australian Corporations', Accounting and Business Research. 26(3), 187-199.

Freedman, M. and Stagliano, A. J. (2008) "Environmental disclosures: electric utilities and Phase 2 of the Clean Air Act." Critical Perspectives on Accounting 19(4), 466-486

Freeman, E. (1984), Strategic Management: A stakeholder approach. London: Pitman.

Gamerschlag, R., Möller, K. and Verbeeten, F (2010), 'Determinants of Voluntary CSR Disclosure: Empirical evidence from Germany', Review of Managerial Science. 5(2/3), 233-262.

Gintschel, A., Markov, S., 2004. The effectiveness of Regulation FD. Journal of Accounting and Economics 37: 293-314.

Gray, R., Kouhy, R. and Lavers, S. (1995), 'Corporate Social and Environmental Reporting: A review of the literature and a longitudinal study of UK disclosure', Accounting, Auditing \& Accountability Journal. 8(2), 44- 77.

Greene, W. H. (2008). Econometric analysis (6th ed). Upper Saddle River, NJ: Prentice Hall.

Hackston, D., and Milne, M. J. (1996). Some determinants of social and environmental disclosures in New Zealand companies. Accounting, Auditing and Accountability Journal, 9(1), 77-108. 
Hasseldine, J., Salama, A. I. I., and Toms, J. S. S. (2005). Quantity versus quality: the impact of environmental disclosures on the reputations of UK Plcs. The British Accounting Review, 37(2), 231-248.

Healy, P., and Palepu, K. (2001), 'Information Asymmetry, Corporate Disclosure and the Capital Markets: A review of the empirical disclosure literature', Journal of Accounting and Economics. 31(1), 405440.

Hooks, J., and van Staden, C. J. (2011). Evaluating environmental disclosures: The relationship between quality and extent measures. The British Accounting Review, 43(3), 200-213.

Hossain, M., Tan, L. M., \& Adams, M., (1994), 'Voluntary Disclosure in an Emerging Capital Market: Some empirical evidence from companies listed on the Kuala Lumpur Stock Exchange', The International Journal of Accounting. 29(4), 334-351.

Hu. Y., and Karbhari. Y. (2015), 'Incentives and Disincentives of Corporate Environmental Disclosure: Evidence from listed companies in China and Malaysia', Thunderbird International Business Review. 57(2), 143-161.

Hu, Y., Zhu, Y., Tucker, J. and Hu, Y. (2018) "Ownership influence and CSR disclosure in China", Accounting Research Journal, 31(1), 8-21.

Huang, C. L., and Kung, F. H. (2010), 'Drivers of Environmental Disclosure and Stakeholder Expectation: Evidence from Taiwan', Journal of Business Ethics. 96(3), 435-451.

Krippendorff, K., (2004) 'Content Analysis: An Introduction to its Methodology', (2nd Ed). Thousand Oak, London: Sage

Li, Q., Luo, W., Wang, Y and Wu, L. (2013), 'Firm Performance, Corporate Ownership, and Corporate Social Responsibility Disclosure in China', Business Ethics: A European Review. 22(2), 159-173.

Liu, X. and Anbumozhi, V. (2009), 'Determinant factors of corporate environmental information disclosure: an empirical study of Chinese listed companies', Journal of Cleaner Production. 17 (6), 593-600.

Liu, X., Yu. Q., Fujitsuka, T., Liu, B., Jun Bi and Shishime, T (2010) Functional mechanisms of mandatory corporate environmental disclosure: an empirical study in China. Journal of Cleaner Production 18 (2010) 823-832

Meng, X. H., Zeng, S.X. and Tam, C.M (2013), 'From Voluntarism to Regulation: A study on ownership, economic performance and corporate environmental information disclosure in China', Journal of Business Ethics. 116(1), 217-232.

Mitchell, R. K., Agle, B. R., \& Wood, D. J. (1997), 'Toward a Theory of Stakeholder Identification and Salience: Defining the principle of who and what really counts', Academy of Management Review. 22(4), 853-886.

Nollet, J., Filis, G. and Mitrokostas, E. (2016) Corporate Social Responsibility and Financial Performance: A non-linear and disaggregated approach. Economic Modelling 52 (2016) 400-407

Qiu, Y., Shaukat, A. and Tharyan, R. (2016) Environmental and social disclosures: Link with corporate financial performance. The British Accounting Review 48 (2016) 102-116

Roberts, R. (1992), 'Determinants of Corporate Social Responsibility Disclosure: An application of stakeholder theory', Accounting, Organizations and Society. 17(6), 595-612.

Roodman, D. (2009). A note on the theme of too many instruments, Oxford Bulletin of Economics and statistics, 71(1), 135-158.

Thomsen, S., Pedersen, T., \& Kvist, H. K. (2006). Blockholder ownership: Effects on firm value in market and control based governance systems. Journal of Corporate finance, 12(2), 246-269. 
Toms, J.S., (2002) "Firm resources, quality signals and the determinants of corporate environmental reputation: some UK evidence" British Accounting Review 34(3), 257-282.

Wang, Y., Li, X., Abdou, H. A., and Ntim, C. G. (2015). Financial development and economic growth in China. Investment Management and Financial Innovations 12(3), 8-18

Woodward, D., Edwards, P., \& Birkin, F. (1996), “Organisational legitimacy and stakeholder information provision”, British journal of management, 7(4), 329-350

Yekini, C. O. (2012) Corporate Community Involvement Disclosure: An Evaluation of the Motivation \& Reality. Doctoral Thesis, De Montfort University, Leicester, UK. Available: https://www.dora.dmu.ac.uk/handle/2086/6910

Yekini, K., Adelopo, I., and Adegbite, E. (2017) 'The impact of community expectations on corporate community involvement disclosures in the UK' Accounting Forum 41(3), 234-252

Yekini, K., Adelopo, I., Androkopolous, P. and Yekini, S., (2015) 'Impact of board independence on the quality of community disclosures in annual reports'. Accounting Forum 39(4), 249-267.

Yekini, K., and Jallow, K. (2012). Corporate community involvement disclosures in annual report: A measure of corporate community development or a signal of CSR observance? Sustainability Accounting, Management and Policy Journal, 3(1), 7-32.

Yu, P. (2007), 'Shareholding Ratio and Financial Restatement', Economic Research. 31(1), 134-144.

Zeng, S.X., Xu, X.D., Dong, Z.Y. and Tam, V.W.Y. (2010), 'Towards Corporate Environmental Information Disclosure: An empirical study in China', Journal of Cleaner Production. 18(12), 1142-1148.

Zeng, S.X., Xu, X.D., Yin, H.T. and Tam, C.M (2012), 'Factors that Drive Chinese Listed Companies in Voluntary Disclosure of Environmental Information', Journal of Business Ethics. 109(3), 309-321.

Zhang, B., Yang, Y. and Bi, J. (2011), 'Tracking the Implementing of Green Credit Policy in China: Topdown perspective and bottom-up reform', Journal of Environmental Management. 92(4), 13211327.

Zhang, L., Mol, A. P. J. He, G., and Lu, Y. (2010) 'An implementation assessment of China's Environmental Information Disclosure Decree’ Journal of Environmental Sciences 2010, 22(10) $1649-1656$

Zhang, Y. and Guan, M. (2009) Empirical Study of the Exterior Factors Affecting Corporate Environmental Disclosures, China Population, Resources and Environment, 6(19): 103-106 (in Chinese) 